Anat. Inst. d. Med. Fak., Univ. Okayama (Vorstand: M. SEKI).

\title{
Die Histometrie des Epithels der Luftwege von Katze und Kaninchen.
}

\author{
猫と家愁の気道上皮の組織測定。 \\ Hideji YASUMITSU 安 光 英二.
}

[Eingegangen am 20. Juni 1955.]

Früher haben OPPIKOFER (1906) über die Dicke des Nasenhöhlenepithels des Menschen und LONIGOFF (1911) über die isolierten Epithelzellen der Trachea der Katze, des Hundes usw. berichtet. Neuerdings haben NAGANUMA (1948) eine histometrische Untersuchung über die Dicke des Epithels und der Basalmembran des Menschen und KUSUHARA (1952) eine Arbeit über das Epithel der unteren Luftwege des Menschen, des Kaninchens usw. durchgeführt. Aber diese Untersuchungen waren offenbar im Sinne einer Vorarbeit eher skizzenhaft oder regional begrenzt. Der Verfasser hat an der karnivoren Katze und am herbivoren Kanin. chen, deren Körper an Größe fast gleich sind, eine genaue Histometrie des Epithels des oberen und unteren Luftweges durchgeführt und die Ergebnisse miteinander verglichen.

\section{Material und Methode.}

Eine männliche $3.5-4 \mathrm{~kg}$ schwere Katze und ein männliches etwa $3 \mathrm{~kg}$ schweres Kaninchen wurden geschlachtet. Es wurden sofort die Schleimhaut der Nasenhöhle und Oberkieferhöhle, der Kehlkopf, die Trachea und ein Teil der Lunge herausgenommen, in 10\% igem Formalin fixiert und in Celloidin eingebettet. Die Nasenmuscheln wurden ohne Befreiung von dem Knochen in Celloidin eingebettet und erst darauf mit Trichloressigsäure entkalkt. Man färbte $15-20 \mu$ dicke Schnitte mit Hämatoxylin und Eosin.

Die Cilienhöhe, die Epitheldicke, die Breite der Flimmerzellen in der Höhe der Mitte ihres Kerns und die Länge und Breite der im Epithel am obersten und basal liegenden Kerne wurden gemessen, und zwar an der Oberkieferhöhle, dem Vorder- und Hinterteil der Nasenscheidewand, dem Vorder- und Hinterteil des Nasenhöhlenbodens, der vorderen Nasenmuschel, der Regio respiratoria der Riechmuschel, der Choana, der Kehlkopfhöhle, dem Anfangs-, Mittel- und Endteil der Trachea, der Teilungsstelle der letzteren, dem Bronchus, den Bronchialästen und den Bronchulen.

Die Messung wurde an den meisten Stellen ohne Auswahl an 200 
Zellen, an der Nasenmuschel aber an je 100 Zellen auf der konvexen und konkaven Fläche vorgenommen. Man maß die Cilienhöhe und die Epitheldicke an je 30 Stellen der konvexen und konkaven Fläche der Nasenmuschel und an 50 Stellen der anderen Teile der Luftwege. Weil die Epitheldicke sich an der membranösen Wand der Trachea und des Bronchus durch die Fixierung beträchtlich verändert, wurde hier keine Messung vorgenommen.

Man benutzte bei der Messung das Okular- und Objektmikrometer. Wenn die Zellgrenze unklar war, wurde manchmal das Phasekontrastmikroskop zur Anwendung gebracht.

In den Tabellen bedeutet die Cilienhöhe die zu der Zelloberfläche senkrechte Höhe. Die Epitheldicke ist der Abstand zwischen der Basis und der Oberfläche des Epithels. Der oben im Epithel liegende Kern bezeichnet den Kern der Flimmerzellen. Seine Höhe ist $(a+b)$, 2, wobei a der Abstand zwischen der Epithelbasis und dem oberen Ende des Kerns der Flimmerzellen und $b$ derjenige zwischen der Epithelbasis und dem unteren Ende des letzteren ist. Es bedeutet ferner $\boldsymbol{M}$ den Mittelwert, $\boldsymbol{m}$ den mittlerer Fehler, $V$ den Variationskoeffizient, Längen-Breitenindex des Zelleibes Breite der Flimmerzelle $\times 100 /$ Epitheldicke und LängenBreitenindex des Kerns Kernbreite $\times 100 /$ Kernlänge.

\section{Befunde und Auswertung.}

A. Ergebnisse der Messungen des Epithels in einzelnen Teilen der Luftwege von Katze und Kaninchen.

1. Oberkieferhöhle (Tabelle 1).

Die Schleimhaut dieser Höhle wird bei der Katze meistens von einem einschichtigen Flimmerepithel, in der Nähe des Höhleneingangs zuweilen aber von einem zweireihigen Flimmerepithel bekleidet. Beim Kaninchen wird sie nur mit einem einschichitigen Flimmerepithel zugedeckt. Becherzellen befinden sich, wenn auch in kleiner Zahl, bei der Katze, dagegen kaum beim Kaninchen. Drüsen entwickeln sich bei beiden Tieren ziemlich gut.

Das Epithel ist dünn. Der Variationskoeffizient der Breite der Flimmerzellen ist bei der Katze auffallend größer. Der Längen-Breitenindex der Zellen ist beim Kaninchen beträchtlich größer.- Der Variationskoeffizient der Breite des Kerns ist wie derjenige des Zelleibes bei der Katze merklich größer. Der Längen Breitenindex des Kerns ist bei der Katze etwa 60, und der Kern ist ellipsoid. Dagegen beträgt der Index des Kaninchens über 100, und der Kern ist rundlich gestaltet.

2. Nasenscheidewand (Tabelle 1).

a) Am V'orderteil. 
Das in der Übergangsstelle der Nasenscheidewand zum Boden der Nasenhöhle befindliche JAKOBSONsche Organ ist von dem komplizierten Riechepithel bekleidet. Die andere Stelle hat durchwegs den Überžug vom zweireihigen Flimmerepithel. Die Becherzellen finden sich selten bei der Katze und noch seltener beim Kaninchen. Die Drüsen kommen bei beiden Tieren reichlich vor.

Der Längen-Breitenindex der Flimmerzellen ist beim Kaninchen beträchtlich größer. Die Kerne der oberen Reihe im Epithel sind beim Kaninchen nahezu rund und ihr Längen-Breitenindex ist beim Kaninchen weit größer. Die basal liegenden Kerne sind bei der Katze rundlich und beim Kaninchen queroval.

b) Am Hinterteil.

Der obere Abschnitt des Hinterteils der Nasenscheidewand ist bei beiden Tieren vom Riechepithel bekleidet, der untere Abschnitt desselben aber bei der Katze meist mit einem zweireihigem, stellenweise mit einem dreireihigem Flimmerepithel und beim Kaninchen immer mit zweireihigem Flimmerepithel. Im Bereich des Flimmerepithels gibt es bei der Katze zahlreiche Becherzellen. Die Drüsen sind besonders bei der Katze reichlich vorhanden.

Die Dicke des Epithels des Hinterteils der Nasenscheidewand ist bei der Katze 1.5 fach so groß wie die des Vorderteils, beim Kaninchen ist aber die Dicke des Epithels in den beiden Teilen beinahe gleich, so daß die Epitheldicke bei der Katze beträchtlich größer ist als beim Kaninchen. Der Variationskoeffizient der Breite der Flimmerzellen ist bei der Katze viel größer. Der Längen-Breitenindex der Flimmerzellen beträgt bei der Katze 17 und beim Kaninchen etwa 35. Die Länge der im Epithel hoch liegenden Kerne ist bei der Katze viel größer, dagegen ist ihre Breite beim Kaninchen etwas größer. Die Kerne sind beim Kaninchen kuglig. Die im Epithel zu unterest gereihten Kerne sind bei der Katze rundlich und beim Kaninchen queroval.

3. Vordere Nasenmuschel (Tabelle 2).

a) An der konkaven Fläche.

Das dünne einschichtige Epithel trägt Cilien. Becherzellen und Drüsen sind nicht reichlich.

Das Epithel ist an diesem Ort der Luftwege bei beiden Tieren am dünnsten. Die Cillien sind beim Kaninchen am kürzesten. Die Zellen sind beim Kaninchen kubisch, bei der Katze aber schlank. Die Kerne sind bei beiden Tieren rundlich.

b) An der konvexen Fläche.

Diese Fläche wird bei beiden Tieren mit einem zweireihigen Flimmerepithel zugedeckt. Becherzellen befinden sich wenig, und Drüsen sind selten.

Das Epithel ist verglichen mit dem an der konkaven Fläche viel 
Tabelle

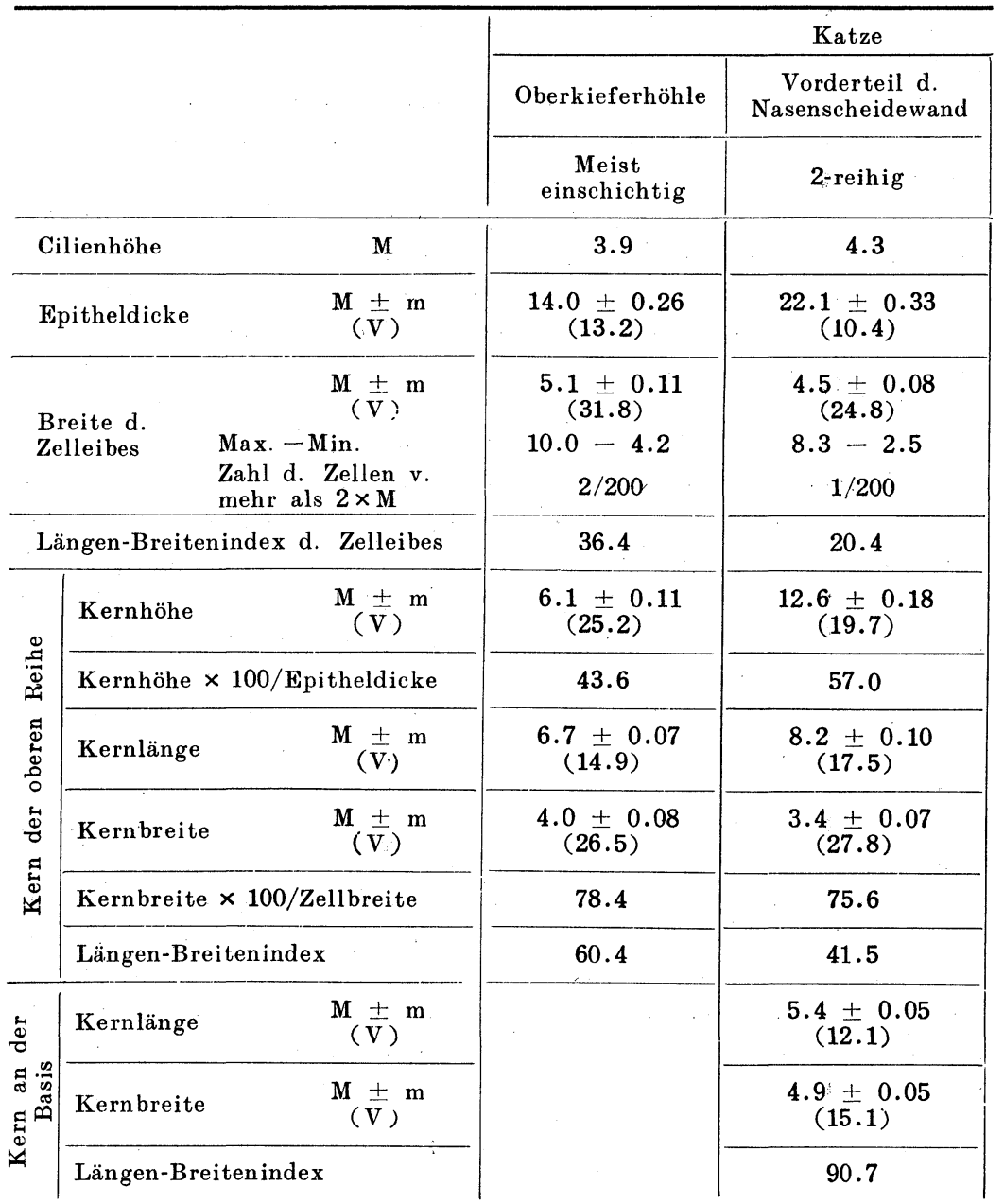

dicker. Der Längen-Breiteṇindex der Zellen beträgt bei beiden Tieren etwa 20. Dər Längen-Breitenindex der im Epithel oben gereihten Kerne ist bei der Katze etwa 45 and beim Kaninchen etwa 55. Die zu unterst im Epithel gelegenen Kerne sind kuglig.

4. Respiratorische Anteile der Riechmuschel (Tabelle 2).

Die Riechmuscheln werden bekanntlich mit einem dicken Riechepithel übergezogen, im vorderen unteren Teil aber stellenweise mit einem gewöhnlichen Epithel. Die Messung wurde an diesem Teil angestellt. 
1.

\begin{tabular}{|c|c|c|c|}
\hline \multirow[b]{2}{*}{$\begin{array}{c}\text { Hinterteil d. } \\
\text { Nasenscheidewand }\end{array}$} & \multicolumn{3}{|c|}{ Kaninchen } \\
\hline & Oberkieferhöhle & $\begin{array}{c}\text { Vorderteil d. } \\
\text { Nasenscheidewand }\end{array}$ & $\begin{array}{l}\text { Hinterteil d. } \\
\text { Nasenscheidewand }\end{array}$ \\
\hline $\begin{array}{c}\text { Meist } \\
\text { 2-reihig }\end{array}$ & Einschichtig & 2-reihig & 2-reihig \\
\hline 5.4 & 5.0 & 3.9 & 4.3 \\
\hline $\begin{array}{c}32.6 \pm 0.43 \\
(9.3)\end{array}$ & $\begin{array}{c}11.8 \pm 0.17 \\
(10.3)\end{array}$ & $17.7 \underset{(6: 4)}{ \pm 0.16}$ & $\begin{array}{c}18.3 \pm 0.47 \\
(18.0)\end{array}$ \\
\hline $\begin{array}{c}5.6 \pm 0.20 \\
(49.4)\end{array}$ & $\begin{array}{c}7.0 \pm 0.08 \\
(15.4)\end{array}$ & $\begin{array}{l}6.6 \pm 0.13 \\
(28.4)\end{array}$ & $\begin{array}{l}6.3 \pm 0.12 \\
(27.4)\end{array}$ \\
\hline $16.7-1.7$ & $10.0-4.2$ & $11.7-3.3$ & $10.0-2.5$ \\
\hline $9 / 200$ & $0 / 200$ & $0 / 200$ & $0 / 200$ \\
\hline 17.2 & 59.3 & 37.2 & 34.4 \\
\hline $\begin{array}{c}17.0 \pm 0.22 \\
(18.2)\end{array}$ & $\begin{array}{l}4.7 \pm 0.10 \\
(31.2)\end{array}$ & $\begin{array}{l}8.5 \pm 0.08 \\
\quad(13.2)\end{array}$ & $\begin{array}{l}9.9 \pm 0.17 \\
(23.6)\end{array}$ \\
\hline 52.1 & 39.8 & 48.0 & 54.1 \\
\hline $\begin{array}{l}9.4 \pm 0.08 \\
(12.8)\end{array}$ & $\begin{array}{l}5.4 \pm 0.05 \\
(14.4)\end{array}$ & $\begin{array}{c}6.6 \pm 0.07 \\
(15.9)\end{array}$ & $\begin{array}{l}5.5 \pm 0.08 \\
\quad(21.6)\end{array}$ \\
\hline $\begin{array}{l}3.5 \pm 0.09 \\
(38.2)\end{array}$ & $\begin{array}{l}5.6 \pm 0.06 \\
(15.3)\end{array}$ & $\begin{array}{l}5.0 \pm 0.09 \\
\quad(26.4)\end{array}$ & $\begin{array}{l}4.4 \pm 0.08 \\
(27.4)\end{array}$ \\
\hline 62.5 & 80.0 & 75.8 & 69.9 \\
\hline 38.1 & 103.8 & 75.8 & 80.0 \\
\hline $\begin{array}{l}4.8 \pm 0.06 \\
(16.3)\end{array}$ & & $\begin{array}{l}3.6 \pm 0.04 \\
(14.2)\end{array}$ & $\begin{array}{l}3.8 \pm 0.05 \\
(17.8)\end{array}$ \\
\hline $\begin{array}{l}5.4 \pm 0.08 \\
(20.1)\end{array}$ & & $\begin{array}{l}7.1 \pm 0.09 \\
(18.1)\end{array}$ & $\begin{array}{l}6.0 \pm 0.09 \\
(21.0)\end{array}$ \\
\hline 112.5 & & 197.0 & 166.5 \\
\hline
\end{tabular}

a) An der konkaven Fläche.

Diese Fläche wird bei der Katze hauptsächlich mit einem zwei reihigem, oft aber mit einschichtigem Flimmerepithel bekleidet. Beim Kaninchen wird sie unregelmäßig mit zweireihigem und einschichtigem Flimmerepithel zugedeckt. Bacherzellen und Drüsen sind kaum zu sehen.

Das Epithel ist immer sehr dünn. Die oben gereihten Kerne sind immer kuglig. Die Kerne der unteren Reihe sind auch kuglig.

b) An der konvexen Fläche.

Man sieht ein zweireihiges Flimmerepithel. Becherzellen und Drüsen 
Tabelle

\begin{tabular}{|c|c|c|c|c|c|}
\hline & & & \multicolumn{3}{|c|}{ Katze } \\
\hline \multirow{2}{*}{\multicolumn{2}{|c|}{$\therefore$}} & . & $\begin{array}{c}\text { Konkave Fl. } \\
\text { d. vorderen } \\
\text { Nasenmuschel }\end{array}$ & $\begin{array}{c}\text { Konvexe } \mathrm{F}] \text {. } \\
\text { d. vorderen } \\
\text { Nasenmuschel }\end{array}$ & $\begin{array}{c}\text { Respirat. } \\
\text { Anteil d. } \\
\text { konkaven Fl. } \\
\text { d.Riechmuschel }\end{array}$ \\
\hline & & & Einschichtig & 2-reihig & Meist 2-reihig \\
\hline \multicolumn{2}{|c|}{ Cilienhöhe } & M & 3.7 & 3.5 & 4.0 \\
\hline \multicolumn{2}{|c|}{ Epitheldicke } & $\mathbf{M} \underset{(\mathrm{V})}{ \pm} \mathbf{m}$ & $13.2 \underset{(9.5)}{ \pm 0.23}$ & $23.4 \pm 0.29$ & $15.4 \underset{(8.9)}{ \pm 0.25}$ \\
\hline \multirow{2}{*}{\multicolumn{2}{|c|}{$\begin{array}{l}\text { Breite d. } \\
\text { Zelleibes }\end{array}$}} & $M \underset{(V)}{ \pm} \mathbf{m}$ & $\begin{array}{l}5.6 \pm 0.13 \\
(23.8)\end{array}$ & $\begin{array}{l}5.1 \pm 0.15 \\
(28.7)\end{array}$ & $\begin{array}{l}6.4 \pm 0.12 \\
(18.1)\end{array}$ \\
\hline & & $\begin{array}{l}\text { - Min. } \\
\text { d. Zellen v. } \\
\text { als } 2 \times \mathrm{M}\end{array}$ & $\begin{array}{c}10.0-3.3 \\
0 / 100\end{array}$ & $\begin{array}{c}10.8-2.5 \\
2 / 100\end{array}$ & $\begin{array}{c}9.2-3.3 \\
0 / 100\end{array}$ \\
\hline \multicolumn{3}{|c|}{ Längen-Breitenindex d. Zelleibes } & 42.4 & 21.8 & 44.8 \\
\hline \multirow{6}{*}{ 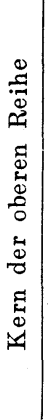 } & Kernhöhe & $\mathrm{M} \underset{(\bar{V})}{ \pm} \mathrm{m}$ & $\begin{array}{c}5.7 \pm 0.08 \\
(14.5)\end{array}$ & $\begin{array}{c}14.5 \pm 0.24 \\
(16.4)\end{array}$ & $\begin{array}{c}7.7 \pm 0.15 \\
(18.8)\end{array}$ \\
\hline & Kernhöhe $\times 1$ & 0/Epitheldicke & 43.2 & 62.0 & 50.0 \\
\hline & Kernlänge & $M \frac{ \pm}{(V)} \mathrm{m}$ & $\begin{array}{c}5.6 \pm 0.07 \\
(11.7)^{\circ}\end{array}$ & $\begin{array}{c}8.8 \pm 0.09 \\
(10.7)\end{array}$ & $\begin{array}{l}6.0 \pm 0.07 \\
(11.8)\end{array}$ \\
\hline & Kernbreite & $\underset{(V)}{\left.\frac{ \pm}{V}\right)} \mathbf{m}$ & $\begin{array}{l}5.1 \pm 0.06 \\
(12.2)\end{array}$ & $\begin{array}{c}3.8 \pm 0.09 \\
(23.4)\end{array}$ & $\begin{array}{c}5.3 \pm 0.10 \\
(19.5)\end{array}$ \\
\hline & Kernbreite $x$ & 100/Zellbreite & 91.1 & 76.5 & 82.8 \\
\hline & Längen-Brei & enindex : & 91.0 & 43.2 & 88.5 \\
\hline \multirow{3}{*}{ 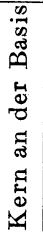 } & Kernlänge & $\mathrm{M} \underset{(\mathrm{V})}{ \pm} \mathrm{m}$ & & $\begin{array}{l}5.2 \pm 0.06 \\
(10.7)\end{array}$ & $\begin{array}{l}4.2 \pm 0.06 \\
(15.0)\end{array}$ \\
\hline & Kernbreite & $\mathrm{M} \underset{(\mathrm{V})}{ \pm} \mathrm{m}$ & & $\begin{array}{c}5.6 \pm 0.06 \\
(10.9)\end{array}$ & $\begin{array}{l}5.1 \pm 0.08 \\
(16.7)\end{array}$ \\
\hline & Längen-Brei & enindex & & 107.8 & 121.3 \\
\hline
\end{tabular}

sind wenig zu sehen. Die Dicke des Epithels ist viel größer als an der konkaven Fläche. Der Längen-Breitenindex der Flimmerzellen beträgt bei der Katze etwa 25, beim Kaninchen etwa 20.

Die im Epithel oben gereihten Kerne sind bei beiden Tieren fast gleich groß und längsoval. Auch die Kerne der basalen Zellen haben bei beiden Tieren Kugelgestalt.

5. Nasenhöhlenboden (Tabelle 3).

a) Am Vorderteil.

Die Höhle ist hier bei der Katze mit einem zwei- oder dreireihigem 
2.

\begin{tabular}{|c|c|c|c|c|}
\hline & \multicolumn{4}{|c|}{ Kaninchen } \\
\hline $\begin{array}{c}\text { Respirat. } \\
\text { Anteil d. } \\
\text { konvexen Fl. } \\
\text { d.Riechmuschel }\end{array}$ & $\begin{array}{l}\text { Konkave Fl. } \\
\text { d. vorderen } \\
\text { Nasenmuschel }\end{array}$ & $\begin{array}{l}\text { Konvexe Fl. } \\
\text { d. vorderen } \\
\text { Nasenmuschel }\end{array}$ & $\begin{array}{c}\text { Respirat. } \\
\text { Anteil d. } \\
\text { konkaven Fl. } \\
\text { d.Riechmuschel }\end{array}$ & $\begin{array}{c}\text { Respirat. } \\
\text { Anteil d. } \\
\text { konvexen Fl. } \\
\text { d. Riechmuschel }\end{array}$ \\
\hline 2 -reihig & Einschichtig & 2-reihig & $\begin{array}{c}\text { 2-reihig od. } \\
\text { einschichtig }\end{array}$ & 2-reihig \\
\hline 4.2 & 2.6 & 3.5 & 4.4 & 4.3 \\
\hline $21.9 \underset{(7.5)}{ \pm} 0.30$ & $\begin{array}{l}8.6 \pm 0.20 \\
(12.5)\end{array}$ & $23.4 \pm 0.61$ & $15.1 \underset{(7.1)}{ \pm 0} 0.20$ & $\begin{array}{c}23.8 \pm 0.66 \\
(15.2)\end{array}$ \\
\hline $\begin{array}{c}5.4 \underset{(23.1)}{ \pm} 0.12 \\
\end{array}$ & $\begin{array}{c}6.7 \pm 0.17 \\
(25.4)\end{array}$ & $\begin{array}{c}4.3 \pm 0.13 \\
(31.1)\end{array}$ & $\begin{array}{c}5.3 \pm 0.12 \\
(22.3)\end{array}$ & $\begin{array}{l}4.7 \pm 0.17 \\
(35.7)\end{array}$ \\
\hline $10.0-3.3$ & $10.0-3.3$ & $8.3-1.7$ & $9.2-3.3$ & $9.2-1.7$ \\
\hline $0 / 100$ & $0 / 100$ & $0 / 100$ & $0 / 100$ & $0 / 100$ \\
\hline 24.6 & 78.0 & 18.4 & 35.1 & 19.7 \\
\hline $\begin{array}{c}11.8 \pm 0.18 \\
(16.2)\end{array}$ & $\begin{array}{l}3.9 \pm 0.11 \\
(27.0)\end{array}$ & $\begin{array}{c}12.6 \pm 0.47 \\
(37.4)\end{array}$ & $\begin{array}{c}7.7 \pm 0.11 \\
(14.6)\end{array}$ & $\begin{array}{c}12.4 \pm 0.22 \\
(17.8)\end{array}$ \\
\hline 53.9 & 45.4 & 53.9 & 51.0 & 52.0 \\
\hline $\begin{array}{c}7.8 \pm 0.09 \\
(11.5)\end{array}$ & $\begin{array}{l}4.2 \pm 0.09 \\
(20.2)\end{array}$ & $\begin{array}{c}6.5 \pm 0.13 \\
(19.8)\end{array}$ & $\begin{array}{c}5.0 \pm 0.09 \\
(17.0)\end{array}$ & $\begin{array}{l}8.5 \pm 0.13 \\
(15.3)\end{array}$ \\
\hline $\begin{array}{l}3.4 \pm 0.13 \\
(37.5)\end{array}$ & $\begin{array}{l}5.1 \pm 0.10 \\
(18.7)\end{array}$ & $\begin{array}{c}3.5 \pm 0.11 \\
(30.5)\end{array}$ & $\begin{array}{c}4.6 \pm 0.08 \\
(17.0)\end{array}$ & $\begin{array}{c}3.3 \pm 0.13 \\
(39.3)\end{array}$ \\
\hline 63.0 . & 76.1 & 81.4 & 86.8 & 70.2 \\
\hline 43.6 & 121.5 & 54.0 & 92.0 & 38.8 \\
\hline $\begin{array}{l}4.4 \pm 0.07 \\
(16.5)\end{array}$ & & $\begin{array}{l}4.2 \pm 0.07 \\
(15.8)\end{array}$ & $\begin{array}{c}4.1 \pm 0.05 \\
(13.0)\end{array}$ & $\begin{array}{c}5.3 \pm 0.07 \\
(13.9)\end{array}$ \\
\hline $\begin{array}{l}5.1 \pm 0.10 \\
(19.5)\end{array}$ & & $\begin{array}{l}4.5 \pm 0.08 \\
(17.8)\end{array}$ & $\begin{array}{l}4.3 \pm 0.07 \\
(15.8)\end{array}$ & $\begin{array}{c}4.7 \pm 0.09 \\
(19.0)\end{array}$ \\
\hline 116.0 & & 107.0 & 105.0 & 88.6 \\
\hline
\end{tabular}

und beim Kaninchen mit zweireihigem Flimmerepithel bekleidet. Becherzellen befinden sich bei der Katze zahlreich und beim Kaninchen etwas weniger. Ähnlich verhält es sich auch mit den Drüsen.

Das hiesige Epithel ist bei beiden Tieren dicker als am Vorderteil der Nasenscheidewand und an der konvexen Fläche der vorderen Nasenmuschel. Der Längen-Breitenindex der Flimmerzellen ist bæi beiden Tieren etwa 20. Die im Epithel oben vorhandenen Kerne sind beim Kaninchen etwas länger gestaltet und zeigen als Längen-Breitenindex etwa 40. Der gleiche Index ist bei der Katze etwa 50. Die tief liegenden Kerne sind 
Tabelle

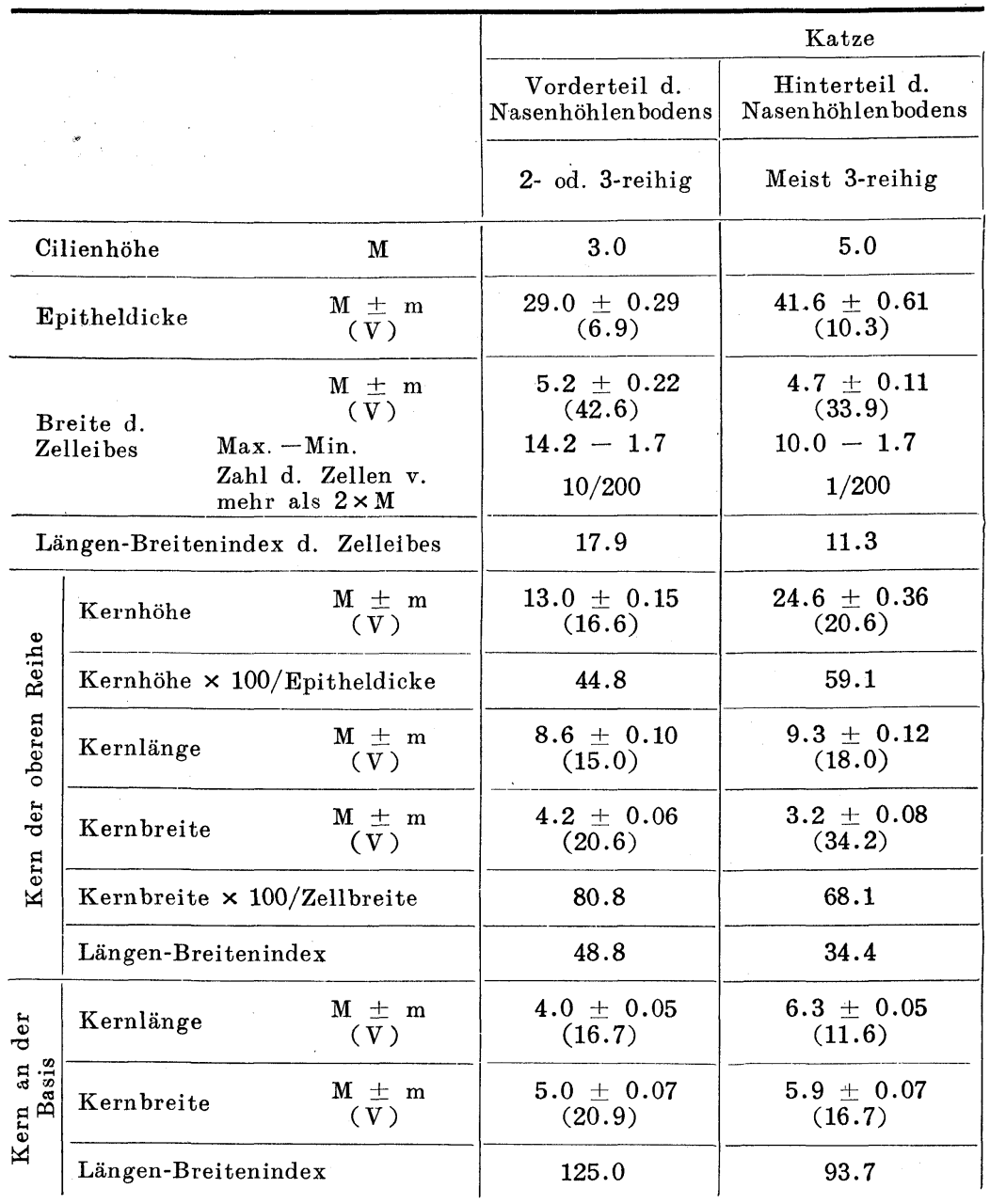

bei beiden Tieren rundlich und gleich groß.

b) Am Hinterteil.

Das Epithel trägt Cilien und ist bezüglich der Kerne meist dreireihig und zum Teil zweireihig. Die Becherzellen sind weniger häufig als am Vorderteil des Nasenhöhlenbodens. Die Drüsen entwickeln sich aber besser. Unter dem Epithel sieht man hier und da Lymphocyteninfiltration.

Das Epithel ist bei der Katze wie auch beim Kaninchen, abgesehen von dem an der Choana, am dicksten im oberen Luftwege. Der Längen- 
3.

\begin{tabular}{|c|c|c|c|}
\hline \multirow[b]{2}{*}{ Choana } & \multicolumn{3}{|c|}{ Kaninchen } \\
\hline & $\begin{array}{l}\text { Vorderteil d. } \\
\text { Nasenhöhlen bodens }\end{array}$ & $\begin{array}{c}\text { Hinterteil d. } \\
\text { Nasenhöhlen bodens }\end{array}$ & Choana \\
\hline 3-reihig & 2-reihig & Meist 3-reihig & Meist 3-reihig \\
\hline 4.3 & 4.7 & 4.0 & 4.8 \\
\hline $\begin{array}{c}45.3 \pm 0.81 \\
(12.6)\end{array}$ & $25.4 \underset{(7.4)}{ \pm 0.27}$ & $\begin{array}{c}35.2 \pm 0.41 \\
(13.7)\end{array}$ & $\begin{array}{c}42.0 \pm 0.65 \\
(10.9)\end{array}$ \\
\hline $\begin{array}{l}5.2 \pm 0.15 \\
(39.8)\end{array}$ & $\begin{array}{c}5.3 \pm 0.12 \\
(32.3)\end{array}$ & $\begin{array}{c}5.5 \pm 0.12 \\
(31.4)\end{array}$ & $\begin{array}{c}4.8 \pm 0.11 \\
(32.3)\end{array}$ \\
\hline $14.2-1.7$ & $12.5-1.7$ & $12.5-1.7$ & $10.0-1.7$ \\
\hline $6 / 200$ & $2 / 200$ & $1 / 200$ & $2 / 200$ \\
\hline 11.5 & 20.8 & 15.6 & 11.4 \\
\hline$\underset{(16.9)}{23.8 \pm 0.28}$ & $\begin{array}{c}13.9 \pm 0.14 \\
(14.0)\end{array}$ & $\begin{array}{c}21.3 \pm 0.41 \\
(27.2)\end{array}$ & $\begin{array}{c}26.9 \pm 0.34 \\
(17.7)\end{array}$ \\
\hline 52.6 & 54.7 & 60.1 & 64.0 \\
\hline $\begin{array}{c}10.1 \pm 0.10 \\
(13.8)\end{array}$ & $\begin{array}{c}9.7 \pm 0.09 \\
(14.0)\end{array}$ & $\begin{array}{l}8.9 \pm 0.09 \\
(14.6)\end{array}$ & $\begin{array}{c}10.2 \pm 0.14 \\
(19.3)\end{array}$ \\
\hline $\begin{array}{l}3.0 \pm 0.08 \\
(41.2)\end{array}$ & $\begin{array}{c}4.0 \pm 0.09 \\
(33.6)\end{array}$ & $\begin{array}{l}3.3 \pm 0.08 \\
(36.3)\end{array}$ & $\begin{array}{l}3.3 \pm 0.07 \\
(29.7)\end{array}$ \\
\hline 57.7 & 75.5 & 60.0 & 68.8 \\
\hline 29.7 & 41.2 & 37.1 & 32.4 \\
\hline $\begin{array}{l}5.8 \pm 0.05 \\
(13.3)\end{array}$ & $\begin{array}{l}4.8 \pm 0.07 \\
(20.0)\end{array}$ & $\begin{array}{l}4.7 \pm 0.05 \\
(15.2)\end{array}$ & $\begin{array}{l}5.7 \pm 0.06 \\
(14.8)\end{array}$ \\
\hline $\begin{array}{l}5.1 \pm 0.06 \\
(16.5)\end{array}$ & $\begin{array}{l}4.7 \pm 0.07 \\
(21.9)\end{array}$ & $\begin{array}{l}4.7 \pm 0.07 \\
(20.4)\end{array}$ & $\begin{array}{l}5.2 \pm 0.07 \\
\quad(19.4)\end{array}$ \\
\hline 87.9 & 98.0 & 100.0 & 91.2 \\
\hline
\end{tabular}

Breitenindex der Flimmerzellen ist bei beiden Tieren $10-15$. Die im Epithel oben liegenden Kerne sind bei beiden Tieren fast gleich groß, ihr Längen-Breitenindex ist etwa 35. Die basal liegenden Kerne haben Kugelgestalt.

6. Choana (Tabelle 3).

Das Epithel ist bei der Katze dreireihig und beim Kaninchen meist dreireihig, aber zuweilen zweireihig. Die Becherzellen kommen bei der Katze zahlreicher vor. Bei beiden Tieren sind viele Drüsen und reichliche Lymphinfiltrationen zu sehen. 
Tabelle

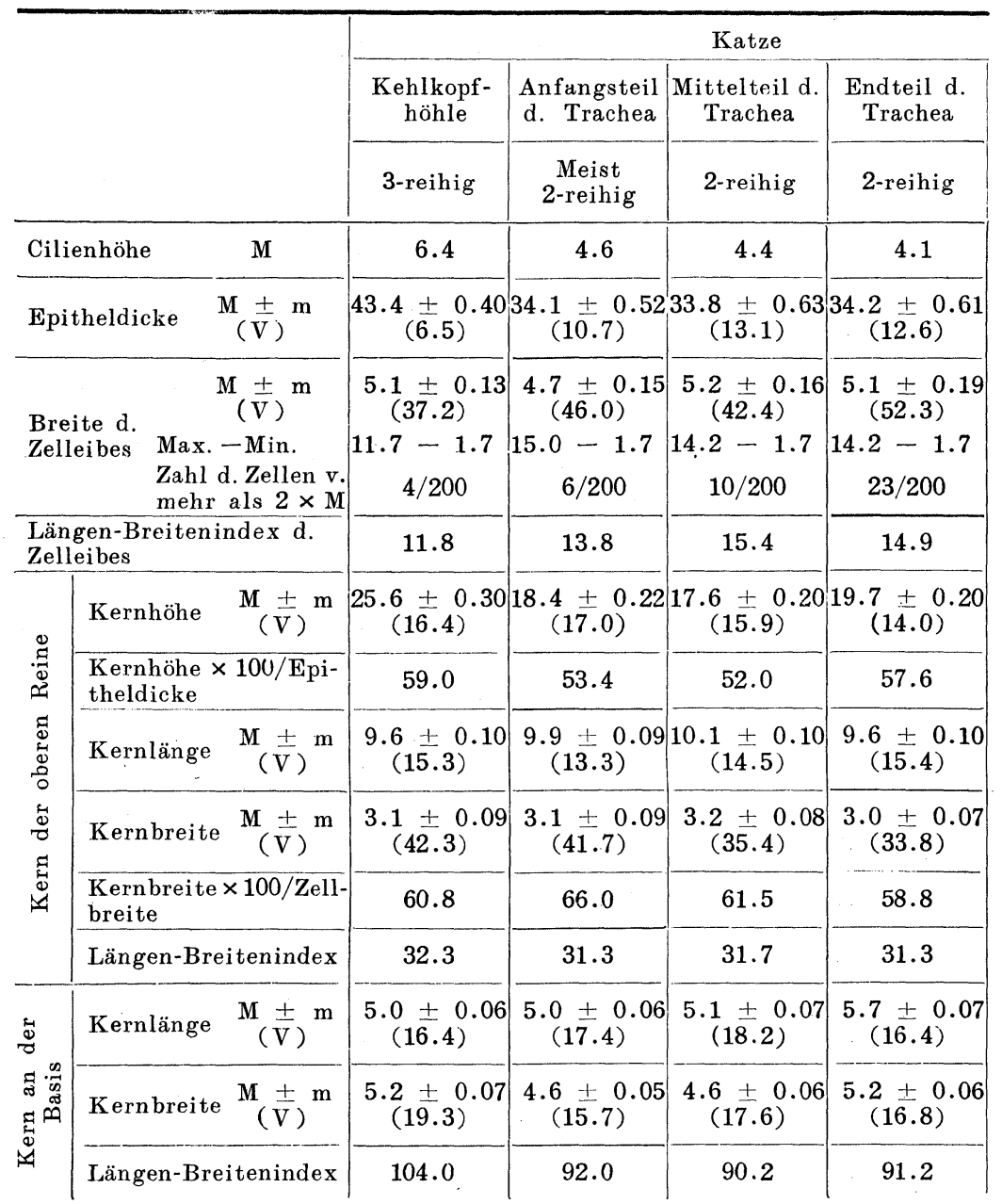

Das Epithel der Choana ist bei beiden Tieren in den Luftwegen am dicksten. Die Flimmerzellen sind lang, aber beträchtlich dünn, und ihr Längen-Breitenindex ist größer als 10. Die im Epithel oben gereihten Kerne sind demzufolge sehr schlank und haben den Längen-Breitenindex von etwa 30. Die basal liegenden Kerne sind kuglig.

7. Kehlkopfhöhle (Tabelle 4).

Kurz vor dem Stimmband wird die Lichtung des Luftweges mit einem dicken geschichteten Plattenepithel übergezogen, welches hinter dem Stimmband bei der Katze in ein dreireihiges und beim Kaninchen 
4.

\begin{tabular}{|c|c|c|c|c|c|}
\hline & \multicolumn{5}{|c|}{ Kaninchen } \\
\hline $\begin{array}{l}\text { Teilungs- } \\
\text { stelle d. } \\
\text { Trachea } \\
\end{array}$ & $\begin{array}{l}\text { Kehlkopf- } \\
\text { höhle }\end{array}$ & $\begin{array}{c}\text { Anfangsteil } \\
\text { d. Trachea }\end{array}$ & $\begin{array}{l}\text { Mittelteil } \\
\text { d. Trachea }\end{array}$ & $\underset{\text { Trachea }}{\text { Endteil d. }}$ & $\begin{array}{l}\text { Teilungs- } \\
\text { stelle d. } \\
\text { Trachea }\end{array}$ \\
\hline $\begin{array}{c}\text { Meist } \\
\text { 2-reihig }\end{array}$ & $\begin{array}{l}\text { 2-oder } \\
\text { 3-reihig }\end{array}$ & 2-reihig & 2-reihig & 2-reihig & 2-reihig \\
\hline 4.2 & 5.2 & 4.2 & 4.1 & 4.1 & 4.2 \\
\hline $37.8 \pm 0.51$ & $29.4 \pm 0.33$ & $\begin{array}{c}21.7 \pm 0.31 \\
(10.0)\end{array}$ & $21.7 \pm 0.15$ & $19.3 \pm 0.24$ & $21.8 \pm 0.20$ \\
\hline $\begin{array}{c}5.0 \pm 0.15 \\
(43.6)\end{array}$ & $\begin{array}{l}4.9 \pm 0.10 \\
(29.8)\end{array}$ & $\begin{array}{c}5.2 \pm 0.12 \\
(32.0)\end{array}$ & $\begin{array}{c}5.0 \pm 0.11 \\
(33.5)\end{array}$ & $\begin{array}{l}5.2 \pm 0.10 \\
(26.6)\end{array}$ & $\begin{array}{c}5.7 \pm 0.12 \\
(28.9)\end{array}$ \\
\hline $13.5-1.7$ & $8.3-1.7$ & $10.8-1.7$ & $10.8-2.5$ & $12.5-2.5$ & $12.5-2.5$ \\
\hline $7 / 200$ & $0 / 200$ & $0 / 200$ & $4 / 200$ & $1 / 200$ & $2 / 200$ \\
\hline 13.2 & 16.7 & 23.8 & 23.4 & 27.0 & 26.2 \\
\hline $\begin{array}{c}18.7 \pm 0.24 \\
(18.1)\end{array}$ & $\begin{array}{c}20.7 \pm 0.15 \\
(10.4)\end{array}$ & $\begin{array}{c}12.7 \pm 0.18 \\
(19.5)\end{array}$ & $\begin{array}{c}13.5 \pm 0.16 \\
(16.9)\end{array}$ & $\begin{array}{c}10.2 \pm 0.13 \\
(17.3)\end{array}$ & $\begin{array}{c}11.2 \pm 0.14 \\
(17.9)\end{array}$ \\
\hline 49.5 & 70.4 & 59.0 & 62.1 & 52.8 & 51.4 \\
\hline $\begin{array}{c}11.1 \pm 0.19 \\
(24.6)\end{array}$ & $\begin{array}{c}9.2 \pm 0.11 \\
(16.5)\end{array}$ & $\begin{array}{c}9.4 \pm 0.09 \\
(13.2)\end{array}$ & $\begin{array}{c}9.2 \pm 0.09 \\
(14.2)\end{array}$ & $\begin{array}{c}8.6 \pm 0.08 \\
(13.5)\end{array}$ & $\begin{array}{c}8.1 \pm 0.08 \\
(12.7)\end{array}$ \\
\hline $\begin{array}{c}3.0 \pm 0.06 \\
(26.2)\end{array}$ & $\begin{array}{c}3.6 \pm 0.09 \\
(33.6)\end{array}$ & $\begin{array}{c}3.9 \pm 0.08 \\
(27.5)\end{array}$ & $\begin{array}{c}3.1 \pm 0.08 \\
(38.2)\end{array}$ & $\begin{array}{c}3.7 \pm 0.08 \\
(30.2)\end{array}$ & $\begin{array}{c}4.1 \pm 0.10 \\
(32.8)\end{array}$ \\
\hline 60.0 & 73.5 & 75.0 & 62.0 & 71.1 & 71.9 \\
\hline 27.0 & 39.1 & 41.5 & $33 \cdot 7$ & 43.0 & 50.5 \\
\hline $4.0 \underset{(25.0)}{ \pm 0.07}$ & $\begin{array}{l}4.3 \pm 0.05 \\
(16.8)\end{array}$ & $\begin{array}{c}4.6 \pm 0.05 \\
(15.7)\end{array}$ & $\begin{array}{c}4.8 \pm 0.04 \\
(11.7)\end{array}$ & $\begin{array}{c}4.7 \pm 0.05 \\
(13.9)\end{array}$ & $\begin{array}{c}4.5 \pm 0.05 \\
(14.9)\end{array}$ \\
\hline $\begin{array}{c}5.3 \pm 0.07 \\
(18.8)\end{array}$ & $\begin{array}{c}4.3 \pm 0.07 \\
(22.0)\end{array}$ & $\begin{array}{c}4.7 \pm 0.04 \\
(13.1)\end{array}$ & $4.5 \pm 0.05$ & $\begin{array}{c}4.7 \pm 0.06 \\
(18.3)\end{array}$ & $\begin{array}{c}4.2 \pm 0.05 \\
(17.5)\end{array}$ \\
\hline 132.3 & 100.0 & 102.0 & 93.8 & 100.0 & 93.4 \\
\hline
\end{tabular}

in ein zwei- oder dreireihiges Flimmerepithel übergeht. Die Messung erfolgte an den letzteren Epithelien. Die Becherzellen und die Drüsen sind bei der Katze reichlich, beim Kaninchen aber weniger vorhanden.

Das Epithel des Kehlkopfes ist bei beiden Tieren am dicksten im unteren Luftwege. Das Epithel ist besonders bei der Katze dick. Die Cilien dieser Gegend sind bei beiden Tieren in den ganzen Luftwegen am längsten. Der Längen-Breitenindex der Flimmerzellen ist bei der Katze wie beim Kaninchen klein und beträgt etwa $10-15$. Die im Epithel 
Tabelle

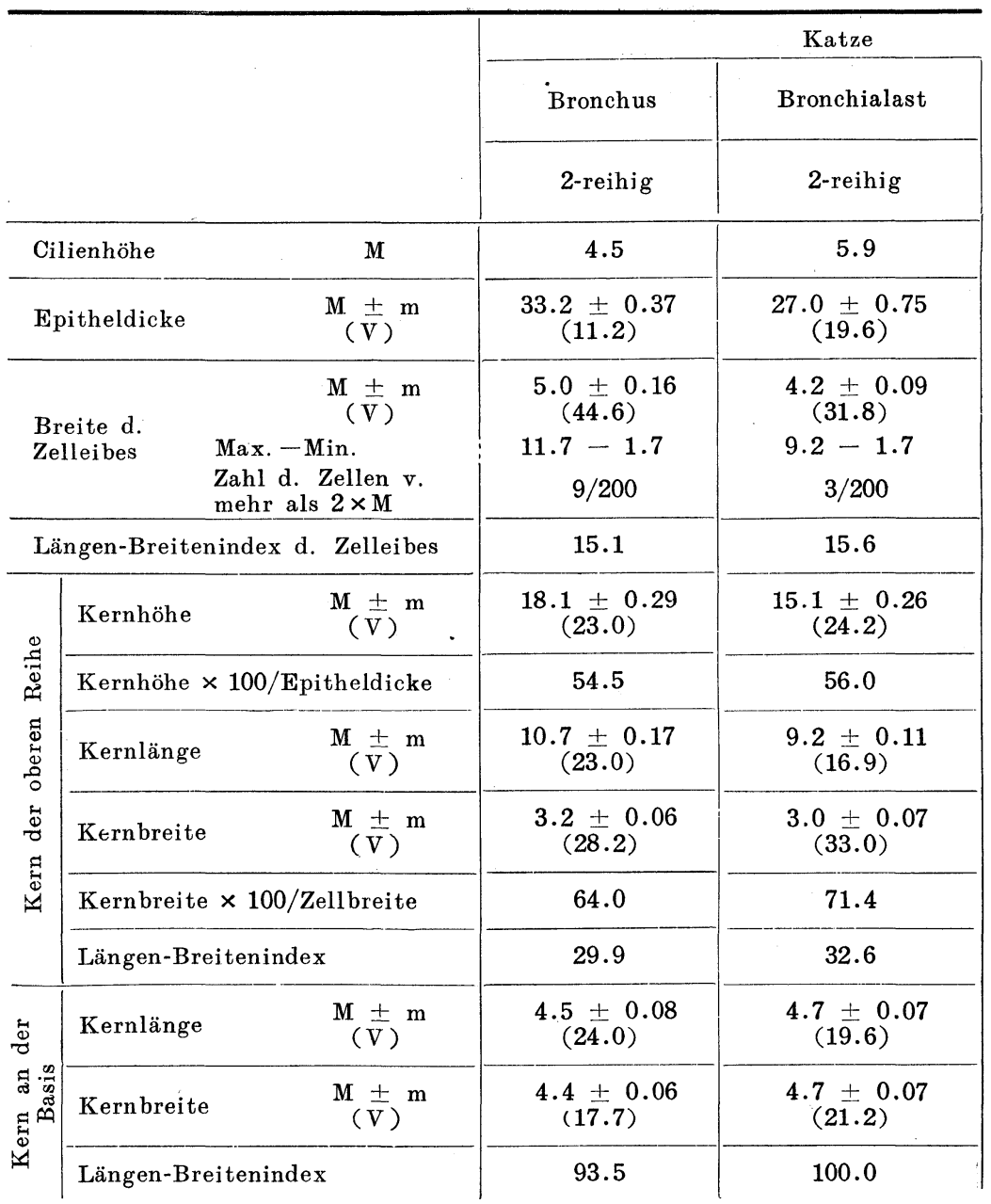

hoch liegenden Kerne sind bei der Katze schlanker und vom LängenBreitenindex etwa 30. Die tief liegenden Kerne haben Kugelgestalt.

8. Trachea (Tabelle 4).

a) Anfangsteil.

Das Epithel ist bei der Katze meistens zweireihig, mitunter aber dreireihig, und beim Kaninchen zweireihig. Becherzellen und Drüsen finden sich bei der Katze reichlich, beim Kaninchen aber weniger.

Das Epithel ist bei der Katze weit dicker als beim Kaninchen. Der 
5.

\begin{tabular}{|c|c|c|c|}
\hline & \multicolumn{3}{|c|}{ Kaninchen } \\
\hline Bronchulus & Bronchus & Bronchialast & Bronchulus \\
\hline Meist einschichtig & 2-reihig & $\begin{array}{l}\text { 2-reihig od. } \\
\text { einschichtig }\end{array}$ & Einschichtig \\
\hline 2.2 & 4.4 & 3.8 & 3.5 \\
\hline $16.8 \underset{(19.5)}{ \pm 0.47}$ & $\begin{array}{c}18.7 \pm 0.50 \\
(18.8)\end{array}$ & $\begin{array}{l}13.0 \pm 0.40 \\
(21.8)\end{array}$ & $12.5 \pm 0.43$ \\
\hline $\begin{array}{l}5.2 \pm 0.11 \\
(30.2)\end{array}$ & $\begin{array}{c}4.8 \pm 0.12 \\
(33.8)\end{array}$ & $\begin{array}{c}5.9 \pm 0.13 \\
(31.5)\end{array}$ & $\begin{array}{c}5.8 \pm 0.12 \\
(29.4)\end{array}$ \\
\hline $10.8-1.7$ & $10.0-1.7$ & $10.8-1.7$ & $11.7-2.5$ \\
\hline $2 / 200$ & $1 / 200$ & $0 / 200$ & $1 / 200$ \\
\hline 31.0 & 25.6 & 45.4 & 46.4 \\
\hline $\begin{array}{c}7.4 \pm 0.15 \\
(29.2)\end{array}$ & $\begin{array}{c}10.4 \pm 0.19 \\
(25.2)\end{array}$ & $\begin{array}{c}8.1 \pm 0.14 \\
(23.7)\end{array}$ & $\begin{array}{c}5.0 \pm 0.12 \\
(34.1)\end{array}$ \\
\hline 44.0 & 55.6 & 62.3 & 40.0 \\
\hline $\begin{array}{c}8.1 \pm 0.11 \\
(20.0)\end{array}$ & $\begin{array}{c}7.7 \pm 0.10 \\
(17.7)\end{array}$ & $\begin{array}{l}5.8 \pm 0.09 \\
(22.1)\end{array}$ & $\begin{array}{c}5.7 \pm 0.08 \\
(20.4)\end{array}$ \\
\hline $\begin{array}{l}3.0 \pm 0.09 \\
(40.6)\end{array}$ & $\begin{array}{l}2.9 \pm 0.10 \\
(17.7)\end{array}$ & $\begin{array}{l}4.3 \pm 0.10 \\
(32.1)\end{array}$ & $\begin{array}{c}4.5 \pm 0.10 \\
(32.0)\end{array}$ \\
\hline 57.7 & 60.4 & 72.9 & 77.6 \\
\hline 37.0 & 37.2 & 74.1 & 114.0 \\
\hline & $\begin{array}{c}4.7 \pm 0.05 \\
(14.0)\end{array}$ & $\begin{array}{c}3.9 \pm 0.05 \\
(16.8)\end{array}$ & \\
\hline & $\begin{array}{c}4.3 \pm 0.05 \\
(17.6)\end{array}$ & $\begin{array}{l}4.4 \pm 0.06 \\
(20.6)\end{array}$ & \\
\hline & 91.5 & 112.8 & \\
\hline
\end{tabular}

Variationskoeffizient der Breite der Flimmerzellen ist auch beträchtlich größer. Der Längen-Breitenindex ist bei der Katze 13.8 und beim Kaninchen 23.8. Die sich im dickeren Epithel oben reihenden Kerne sind bei der Katze im Epithel höher vohanden als beim Kaninchen, aber wenn man die Dicke des Epithels berücksichtigt, liegen die Kerne eher beim Kaninchen verhältnismäßig höher. Der Längen-Breitenindex der oben gereihten Kerne beträgt bei der Katze etwa 30 und beim Kaninchen etwa 40. Die Kerne in der Epithelbasis haben immer kuglige Gestalt.

b) Mittelteil. 
Dieser Teil wird bei der Katze wie beim Kaninchen mit einem zweireihigem Flimmerepithel bekleidet. Becherzellen kommen bei der Katze sehr reichlich vor, dagegen viel weniger beim Kaninchen. Drüsen finden sich bei der Katze reichlich, beim Kaninchen aber in geringerem Maße.

Das Epithel ist bei der Katze bei weitem dicker. Der Längen-Breitenindex der Flimmerzellen ist bei der Katze etwa 15 und beim Kaninchen etwa 25. Die im Epithel hoch liegenden Kerne sind bei beiden Tieren längsoval. Die Kerne an der Basis sind dagegen kuglig.

c) Endteil.

Das Epithel ist immer zweireihig. Die Becherzellen dieses Teils sind bei der Katze unter allen von mir untersuchten Teilen der Luftwege am zahlreichsten, beim Kaninchen aber viel weniger. Auch Drüsen entwickeln sich bei der Katze beträchtlich.

Das Epithel ist bei der Katze bei weitẻm dicker. Die im Epithel oben gereihten Kerne sind bei der Katze länger und dünner. Die tief liegenden Kerne haben bei beiden Tieren Kugelgestalt.

9. Teilungsstelle der Tracea (Tabelle 4).

Das Epithel ist bei der Katze meist zweireihig, zuweilen aber dreireihig, und beim Kaninchen immer zweireihig. Becherzellen und Drüsen kommen bei der Katze weitaus reichlicher vor.

Das Epithel ist bei der Katze viel dicker. Der Variationskoeffizient der Breite der hiesigen Flimmerzellen ist auch bei der Katze viel größer. Der Längen-Breitenindex der Flimmerzellen ist beim Kaninchen 26 und bei der Katze etwa halb so groß. Die im Epithel hoch liegenden Kerne sind bei der Katze länger, aber dünner, ihr Längen-Breitenindex ist bei der Katze 27 und beim Kaninchen etwa 50.

10. Bronchus (Tabelle 5).

Im zweireihigen Flimmerepithel sieht man bei der Katze viele und beim Kaninchen weniger Becherzellen.

Das Epithel ist ein wenig dünner als das der Trachea. Es ist bei der Katze viel dicker als beim Kaninchen. Der Längen-Breitenindex der Flimmerzellen ist beim Kaninchen 25.6 und bei der Katze 15.1. Die Kerne der oberen Reihe im Epithel sind längsoval, die der tiefsten Reihe aber kuglig.

\section{Bronchialast (Tabelle 5).}

Ein dickerer Bronchialast wird bei der Katze mit einem zweireihigen, beim Kaninchen aber mit einem zweireihigen oder einschichtigen Flimmerepithel bedeckt. Es gibt bei der Katze wenige Becherzellen, beim Kaninchen aber sind sie kaum vorhanden. Drüsen werden an dieser Stelle bei weitem seltner getroffen als im Bronchus. Sie sind aber bei 
der Katze mehr zu finden als beim Kaninchen.

Das Epithel ist bei der Katze viel dicker.: Der Längen-Breitenindex der Flimmerzellen beträgt beim Kaninchen 45 und ist dreimal so groß wie bei der Katze. Die im Epithel oben liegenden Kerne sind bei der Katze länglich und beim Kaninchen schon kuglig.

12. Bronchulus (Tabelle 5).

Der Bronchulus führt bei der Katze ein meist einschichtiges, zuweilen zweireihiges Flimmerepithel und beim Kaninchen fast immer ein einschichtiges Flimmerepithel. Bei beiden Tieren nehmen die Becherzellen sehr an Zahl ab, doch werden Drüsen bei der Katze häufiger gefunden.

Das Epithel ist bei beiden Tieren am dünnsten unter allen von mir untersuchten Teilen des unteren Luftweges. Die Kerne der Epithelzellen sind bei der Katze meist längsoval, uud ihr Längen-Breitenindex ist ein Drittel desjenigen des Kaninchens.

\section{B. Umfassende Übersicht über die ermittelten Werte des Epithels in den Luftwegen.}

\section{1. Über die Dicke des Epithels.}

An der menschlichen unteren Nasenmuschel beobachtete OPPIKOFER (1906), daß das Epithel im Hinterteil dicker ist als im Vorderteil. SCHUMACHER (1925) stellte ferner fest, daß das Epithel an der konvexen Fläche der Nasenmuschel merklich dicker ist als an ihrer konkaven Fläche. Es ist auch wohl bekannt, daß das Epithel der Nasennebenhöhlen dünner ist als das der Haupthöhle, und daß mit der wiederholten Verästelung der Bronchialäste und Bronchulen das Epithel immer dünner wird. Nach meiner genaueren Messung des Epithels der oberen Luftwege ordnet sich ihre Dicke bei der Katze in folgender Reihenfolge: konkave Fläche der vorderen Nasenmuschel $<$ Oberkieferhöhle $<$ konkave Fläche der Riechmuschel $<$ konvexe Fläche der Riechmuschel < Vorderteil der Nasenscheidewand $<$ konvexe Fläche der vorderen Nasenmuschel $<$ Vorderteil des Nasenhöhlenbodens $<$ Hinterteil der Nasenscheidewand $<$ Hinterteil des Nasenhöhlenbodens < Choana, und beim Kaninchen in folgender Rejhenfolge : konkave Fläche der vorderen Nasenmuschel $<$ Oberkieferhöhle $<$ konkave Fläche der Riechmuschel $<$ Vorderteil der Nasenscheidewand $<$ Hinterteil der Nasenscheidewand $<$ konvexe Fläche der vorderen Nasenmuschel $<$ konvexe Fläche der Riechmuschel $<$ Vorderteil des Nasenhöhlenbodens $<$ Hinterteil des Nasenhöhlenbodens < Choana. Die Dicke des Epithels der unteren Luftwege ist bei der Katze : Bronchulus $<$ Bronchialast $<$ Bronchus $<$ Mittel-, Anfangs- und Endteil der Trachea $<$ Teilungsstelle der Trachea $<$ Kehl- 
kopfhöhle, und beim Kaninchen : Bronchulus $<$ Bronchialast $<$ Bronchus $<$ Endteil der Trachea $<$ Mittel- und Anfangsteil und Teilungsstelle der Trachea $<$ Kehlkopfhöhle.

Daraus folgt, daß in den oberen Luftwegen, 1. das Epithel der Oberkieferhöhle und der konkaven Fläche der Nasenmuschel beträchtlich dünner ist als das der anderen Teile der Nasenhöhle, 2. in der Nasenscheidewand und an dem Nasenhöhlenboden das Epithel im Hinterteil dicker ist als im Vorderteil, 3. das Epithel des Nasenhöhlenbodens dicker ist als das der Nasenscheidewand und der Nasenmuschel, 4. das Epithel der Choana am dicksten ist. In den unteren Luftwegen ist das Epithel in der Kehlkopfhöhle am dicksten und wird, abgesehen von der Teilungsstelle der Trachea, nach der Peripherie des Luftweges immer dünner.

In Abb. 1 ist die Dicke des Epithels der Luftwege in der Reihenfolge übersichtlich dargestellt. Man ersieht daraus, daß die größte Dicke bei der Choana liegt. Die Flimmerbewegung des Epithels richtet sich in den oberen Luftwegen nach hinten, und in den unteren nach vorn, folglich versammeln sich die Sekrete in der Rachenhöhle. So hat es den Anschein, daß das Epithel um so dicker ist je mehr Sekrete es trägt. Viel wichtiger ist aber die Beziehung zu der Luftströmung. Die Geschwindigkeit der Luftströmung in der menschlichen Nasenhöhle ist, worauf NAKAMURA (1951) hingewiesen hat, am kleinsten am vorderen Ende des unteren Nasengangs und am größten in dem engsten Nasenrachenraum. In den unteren Luftwegen nimmt der Inhalt der Gesammtquerschnitte mit der Verästelung zu und der Strömungswiederstand wird, wie es ROHRER (1915) bemerkt hat, immer kleiner (s. Abb. 2). Die Dicke des Epithels wächst also mit der Verstärkung der mechanischen Wirkung der Luftströmung. In der Oberkieferhöhle und an der konkaven Fläche der Nasenmuschel, in und an welcher keine starke Luftströmung stattfindet, ist das Epithel dagegen sehr dünn.

Vergleicht man die Dick des Epithels der Luftwege der Katze und des Kaninchens, so ergibt sich, daß das Epithel im allgemeinen bei der Katze dicker ist als beim Kaninchen, daß dieser Unterschied im oberen Lufiwege kleiner und im unteren größer ist. Becherzellen und Drüsen kommen bei der Katze reichlich in den ganzen Luftwegen vor, beim Kaninchen aber in den unteren Luftwegen auffallend wenig.

\section{2. Über die Cilienhöhe.}

Die Cilien sind bei beiden Tieren in der Höhle des Kehlkopfes am längsten (s. Abb. 1). Sie sind an der konkaven Fläche der vorderen Nasenmuschel des Kaninchens auffallend kurz. An den anderen Orten sind die Cilien merkwürdigerweise von fast gleicher Länge, ausgenommen sind die sehr dünnen Bronchulen. 


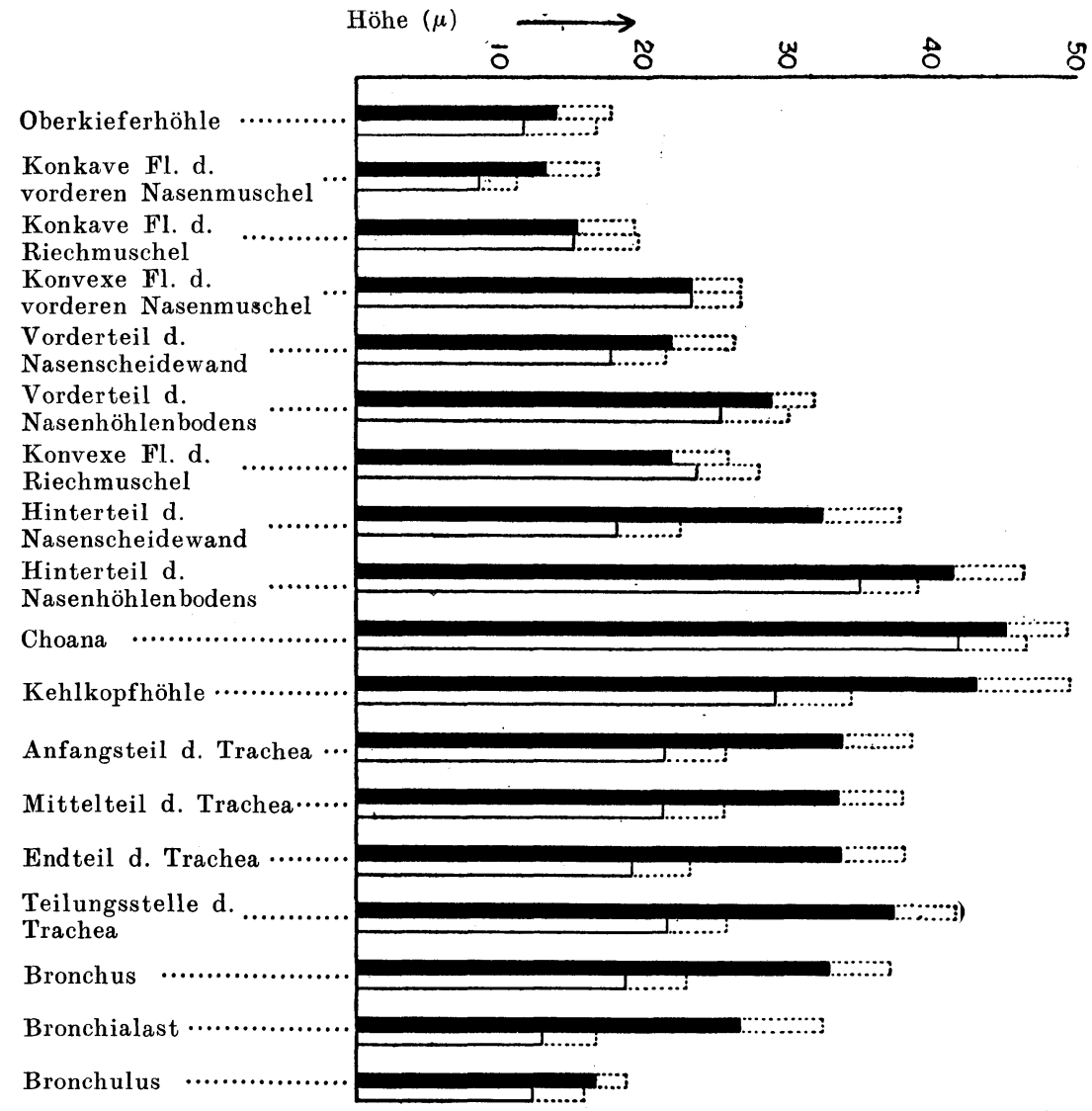

Abb. 1. Epitheldicke der Katze (schwarz) und des Kaninchens (weiß) und die Höhe der übergetragenen Cilien (in punktierten Linien).

\section{3. Über die Breite der Flimmerzellen.}

Zwischen der Epitheldicke und der Breite der Flimmerzellen besteht keine regelmäßige Beziehung, ebensowenig zwischen den Breiten der Flimmerzellen der beiden Tiere.

Bei der Katze sind manchmal, wie in der Zeile ,Zahl d. Zellen v. mehl als $2 \mathrm{M}^{\prime \prime}$ der Breite des Zelleibes in Tabelle $1-5$ gezeigt wird, enorm breite Flimmerzellen beträchtlich mehr vorhanden als beim Kaninchen. Ferner ist der Variationskoeffizient der Breite der Flimmerzellen bei der Katze größer. Solche Unterschied zwischen den beiden Tieren sind in dem unteren Luftwege bedeutender als im oberen. Es handelt sich vielleicht um ein zahlreicheres Vorkommen der Übergansformen zwischen Flimmerzellen und Becherzellen. 


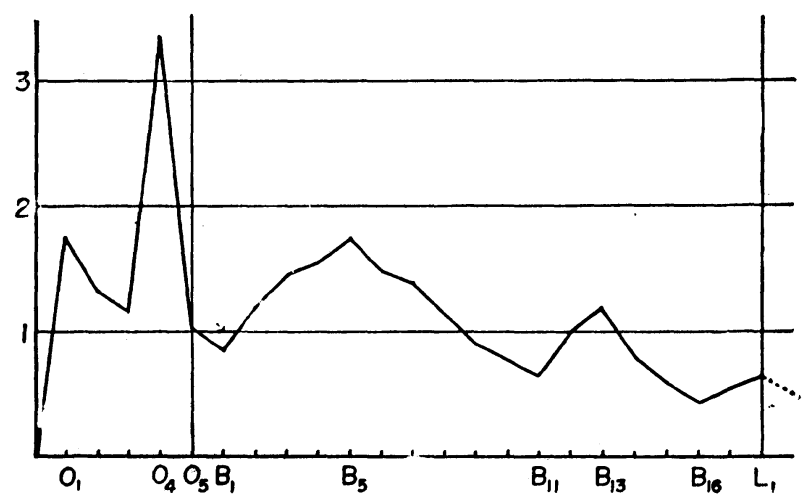

Abb. 2. Strömungsgeschwindichkeit der Luft von der Nasenöffnung bis zu den Alveolen, nach F. ROHRER. $O_{1}$ bis $O_{3}$ : obere Luftwege; $B_{i}$ bis $B_{17}$ : Bronchialwege ; $L_{1} \rightarrow$ : Lobularsystem. Strömungsgeschwindichkeit in Trachea $=1$.

\section{4. Über den Längen-Breitenindex der Flimmerzellen.}

Die Flimmerzellen mit dem Längen-Breitenindex unter 15 finden sich bei der Katze in dem Hinterteil des Nasenhöhlenbodens, der Choana und dem ganzen unteren Luftwege mit Ausnahme von den Bronchulen und beim Kaninchen nur in dem Hinterteil des Nasenhöhlenbodens und der Choana. Die Flimmerzellen mit dem Index 16-20 sind bei der Katze in der Nasenscheidewand und dem Vorderteil des Nasenhöhlenbodens und beim Kaninchen in dem Vorderteil des Nasenhöhlenbodens, der konvexen Fläche der Nasenmuschel und der Kehlkopfhöhle zu sehen. Die Flimmerzellen mit dem Index 21-30 befinden sich bei der Katze an der konvexen Fläche der Nasenmuschel und beim Kaninchen in der Trachea, der Teilungsstelle derselben und dem Bronchus. Die Flimmerzellen mit dem Index 31-40 sind bei der Katze in der Oberkieferhöhle und den Bronchulen und beim Kaninchen in der Nasenscheidewand und an der konkaven Fläche der Riechmuschel vorhanden. Die Flimmerzellen mit dem Index 41-50 werden bei der Katze nur an der konkaven Fläche der Nasenmuschel und beim Kaninchen in den Bronchialästen und den Bronchulen gesehen. Der Längen-Breitenindex der Zellen beträgt in der Oberkieferhöhle des Kaninchens etwa 60, und an der konkaven Fläche seiner vorderen Nasenmuschel sogar etwa 80, und die Zellen sind annähernd kubisch. Aus all diesem geht hervor, daß die Flimmerzellen in einem dickeren Epithel einen kleineren Längen-Breitenindex haben.

5. Über die Höhe der sich im Epithel oben gereihten Kerne und Länge des Hauptabschnittes der Flimmerzellen.

Man bezeichnet den Abstand des Mittelpunktes des Kerns von der 
Basis des Epithels als die Höhe des Kerns. Die Höhe der im Epithel hoch liegenden Kerne ist im allgemeinen bei der Katze grỏßer als beim Kaninchen. Aber die relative Hohe der Kerne, bezogen auf Epitheldicke, ist beim Kaninchen oft größer.

Beim mehrreihigen Flimmerepithel wird der untere Abschnitt der Flimmerzelle von den Ersatszellen gedrückt und geschmälert. Der Hauptabschnitt der Zelle läuft in der Höhe des unteren Endes des Kerns in einem Konus aus. Die Länge des Hauptschnittes der Zelle (L) wird also nach der Formel $\mathrm{L}=\mathrm{a}-\mathrm{b}+(\mathrm{c} / 2)$ berechnet, wobei a die Epitheldicke, b die Höhe des Kerns (des Mittelpunktes desselben) und c die Länge des Kerns bedeuten (Tabelle 6). Die so berechnete Länge des Hauptabschnttes der Flimmerzellen ist wie die Dicke des Epithels in der Oberkieferhöhle und an der konkaven Fläche der Nasenmuschel besonders klein und in der Grenzgegend zwischen dem oberen und un-

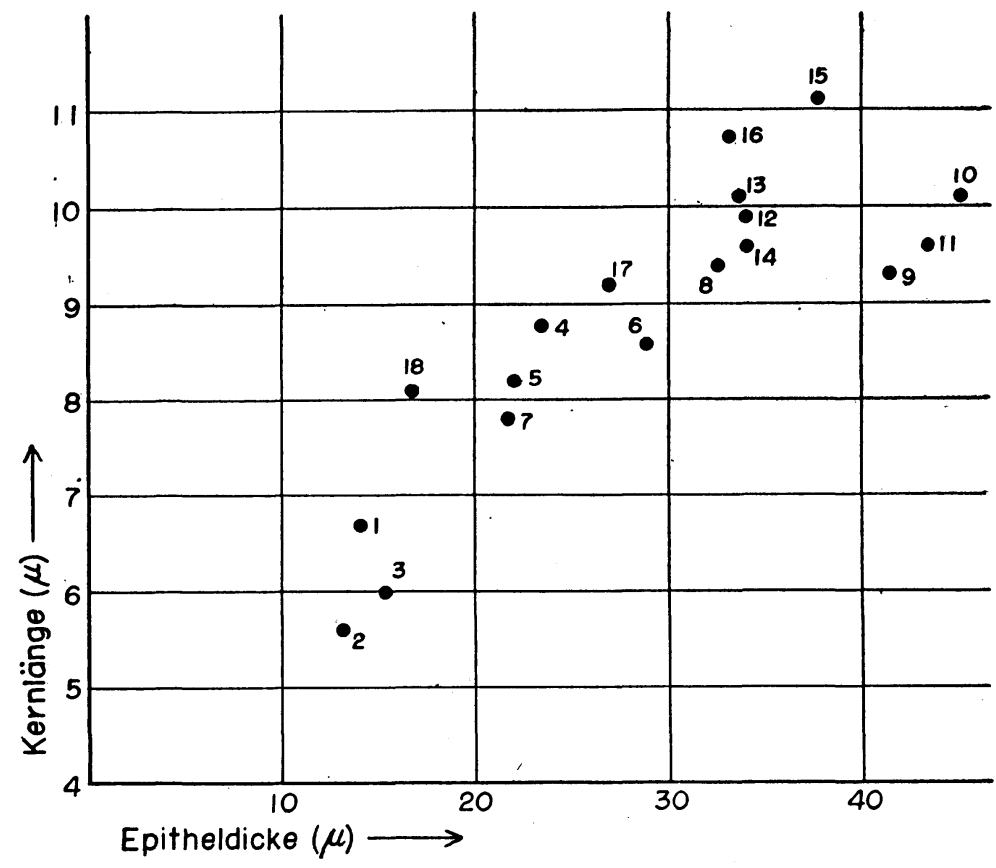

Abb. 3. Epitheldicke und Länge der Kerne, die sich im Epithel oben reihen (bei der Katze). 1 Oberkieferhöhle, 2 konkave Fl. d. vorderen Nasenmuschel, 3 konkave Fl. d. Riechmuschel, 4 konvexe Fl. d. vorderen Nasenmuschel, 5 Vorderteil d. Nasenscheidewand, 6 Vorderteil d. Nasenhöhlenbodens, 7 konvexe Fl. d. Riechmuschel, 8 Hinterteil d. Nasenscheidewand, 9 Hinterteil d. Nasenhöhlenbodens, 10 Choana, 11 Kehlkopfhöhle, 12 Anfangstei1 d. Trachea, 13 Mittelteil d. Trachea, 14 Endteil d. Trachea, 15 Teilungsstelle d. Trachea, 16 Bronchus, 17 Bronchialast, 18 Bronchulus. 


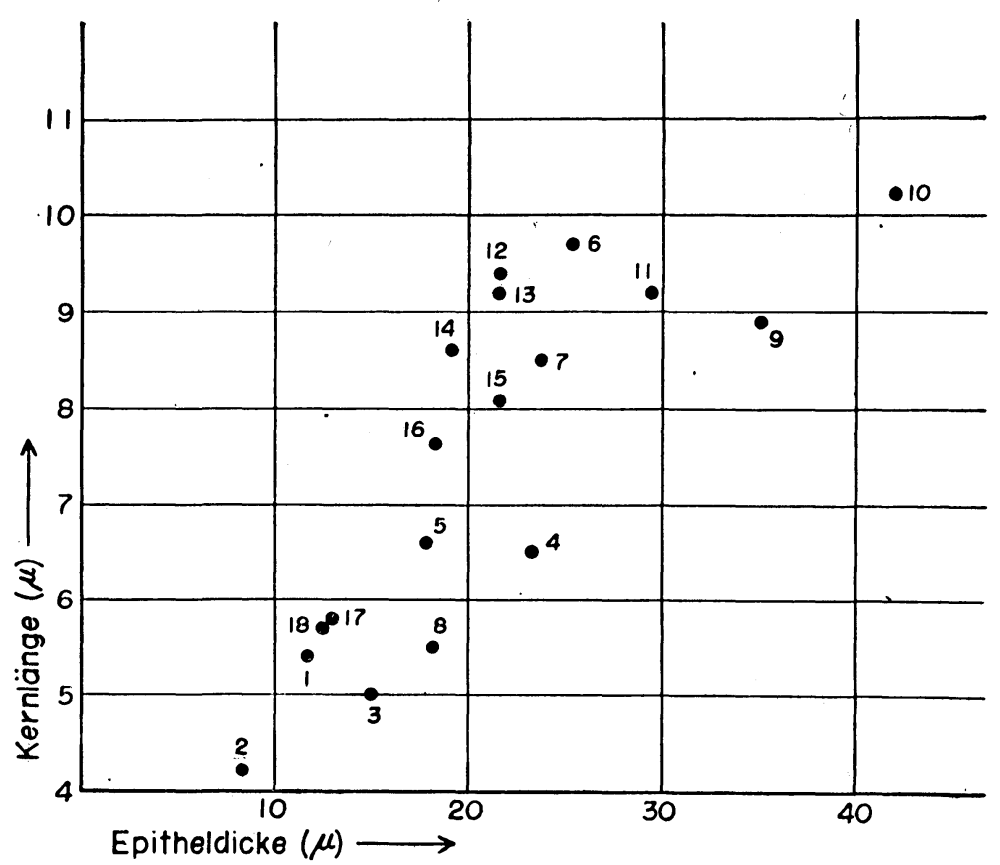

Abb. 4. Epitheldicke und Länge der Kerne, die sich im Epithel oben reihen. (beim Kaninchen). 1 Oberkieferhöhle, 2 konkave Fl. d. vorderen Nasenmuschel, 3 konkave Fl. d. Riechmuschel, 4 konvexe Fl. d. vorderen Nasenmuschel, 5 Vorderteil d. Nasenscheidewand, 6 Vorderteil d. Nasenhöhlenbodens, 7 konvexe Fl. d. Riechmuschel, 8 Hinterteil d. Nasenscheidewand, 9 Hinterteil d. Nasenhöhlenbodens, 10 Choana, 11 Kehlkopfhöhle, 12 Anfangsteil d. Trachea, 13 Mittelteil d. Trachea, 14 Endteil d. Trachea, 15 Teilungsstelle d. Trachea, 16 Bronchus, 17 Bronchialast, 18 Bronchulus.

teren Luftweges am größten. Die Länge ist bei der Katze in der Regel größer als beim Kaninchen. Dieser Unterschied zwischen den beiden Tieren ist überhaupt im unteren Luftwege größer als im oberen.

\section{6. Über die Länge der im Epithel oben gereihten Kerne.}

Diese Kerne gehören zu den Flimmerzellen. Die Länge des Kerns der Flimmerzellen ist abgesehen von wenigen Ausnahmen größer in dickeren Epithelien (Abb. 3 u. 4). Die Kernlänge entspricht einem Hundertsatz von 40-70 der Länge des Hauptschnittes der Zelle. Ihr Wert des unteren Luftweges ist bei der Katze mit Ausnahme von den Bronchulen immer kleiner als beim Kaninchen, aber im oberen Luftwege existiert keine solche Differenz zwischen den beiden Tieren (Tabelle 6). 
Tabelle 6 .

\begin{tabular}{|c|c|c|c|c|c|c|}
\hline & \multicolumn{3}{|c|}{ Katze } & \multicolumn{3}{|c|}{ Kaninchen } \\
\hline & \begin{tabular}{|c|}
$\begin{array}{c}\text { Länge d. } \\
\text { Flimmer- } \\
\text { zellen } \\
\text { (L) }\end{array}$ \\
\end{tabular} & \begin{tabular}{|c|} 
Länge d. \\
Flimmer- \\
zellkerne \\
$(1)$
\end{tabular} & $\frac{1 \times 100}{\mathrm{~L}}$ & \begin{tabular}{|c|} 
Länge d. \\
Flimmer- \\
zellen \\
$\left(\mathrm{L}^{\prime}\right)$
\end{tabular} & $\begin{array}{c}\text { Länge d. } \\
\text { Flimmer- } \\
\text { zellkerne } \\
\left(1^{\prime}\right)\end{array}$ & $\frac{1^{\prime} \times 100}{L^{\prime}}$ \\
\hline Oberkieferhöhle & 11.3 & 6.7 & 59.3 & 9.8 & 5.4 & 55.1 \\
\hline $\begin{array}{l}\text { Vorderteil d. } \\
\text { Nasenscheidewand }\end{array}$ & 13.6 & 8.2 & 60.3 & 12.5 & 6.6 & 52.8 \\
\hline $\begin{array}{l}\text { Hinterteil d. } \\
\text { Nasenscheidewand }\end{array}$ & 20.3 & 9.4 & 46.3 & 11.2 & 5.5 & 49.1 \\
\hline $\begin{array}{l}\text { Konkave Fl. d. } \\
\text { vorderen Muschel }\end{array}$ & 10.3 & 5.6 & 54.4 & 6.8 & 4.2 & 61.8 \\
\hline $\begin{array}{l}\text { Konvexe Fl. d. } \\
\text { vorderen Muschel }\end{array}$ & 13.3 & 8.8 & 66.2 & 14.1 & 6.5 & 46.1 \\
\hline $\begin{array}{l}\text { Konkave Fl. d. } \\
\text { Riechmuschel }\end{array}$ & 10.7 & 6.0 & 56.1 & 9.9 & 5.0 & 50.5 \\
\hline $\begin{array}{l}\text { Konvexe Fl. d. } \\
\text { Riechmuschel }\end{array}$ & 14.0 & 7.8 & 55.7 & 15.7 & 8.5 & 54.1. \\
\hline $\begin{array}{l}\text { Vorderteil d. } \\
\text { Nasenhöhlenbodens }\end{array}$ & 20.3 & 8.6 & 42.4 & 16.4 & 9.7 & 59.1 \\
\hline $\begin{array}{l}\text { Hinterteil d. } \\
\text { Nasenhöhlenbodens }\end{array}$ & 21.7 & 9.3 & 42.9 & 18.4 & 8.9 & 48.3 \\
\hline Choana & 26.6 & 10.1 & 38.0 & 20.2 & 10.2 & 50.5 \\
\hline Kehlkopf höhle & 22.6 & 9.6 & 42.5 & 13.3 & 9.2 & 69.0 \\
\hline $\begin{array}{l}\text { Anfangsteil d. } \\
\text { Trachea }\end{array}$ & 20.7 & 9.9 & 47.8 & 13.7 & 9.4 & 68.6 \\
\hline $\begin{array}{l}\text { Mittelteil d. } \\
\text { Trachea }\end{array}$ & 21.3 & 10.1 & 47.4 & 12.8 & 9.2 & 71.9 \\
\hline Endteil d. Trachea & 19.3 & 9.6 & 49.7 & 13.4 & 8.6 & 64.2 \\
\hline $\begin{array}{l}\text { Teilungsstelle } \mathrm{d} \text {. } \\
\text { Trachea }\end{array}$ & 24.7 & 11.1 & 44.9 & $14 . ?$ & 8.1 & 55.1 \\
\hline Bronchus & 20.5 & 10.7 & 52.2 & 12.2 & 7.7 & 63.1 \\
\hline Bronchialast & 16.5 & 9.2 & 56.0 & 7.8 & 5.8 & 74.4 \\
\hline Bronchulus & 13.5 & 8.1 & 60.0 & 10.2 & 5.7 & 55.9 \\
\hline
\end{tabular}

7. Über die Breite der sich im Epithel oben gereihten Kerne.

Kürzere Kerne der Flimmerzellen sind meistens breiter. Die Kerne sind beim Kaninchens meistens breiter gestaltet als bei der Katze.

Das Verhältnis der Kern- und Zelleibbreite der Flimmerzelle ist bei der Katze 55-90\%, im Mittel 69\% und beim Kaninchen $60-85 \%$, im Mittel $73 \%$. Der Wert des unteren Luftweges ist beim Kaninchen meist größer.

8. Über den Längen-Breitenindex der im Epithel oben gereihten Kerne.

Der Index der Kerne erweist sich bei der Katze zumeist als kleiner als beim Kaninchen. An vielen Orten ist der Wert 30-50, und die Kerne 
haben Eigestalt. Der Index beträgt mehr als 60 in der Oberkieferhöhle der Katze sowie an der Nasenscheidewand und den Bronchialästen usw. des Kaninchens. An der konkaven Fläche der Nasenmuschel der Katze sowie in der Oberkieferhöhle, an der konkaven Fläche der Nasenmuschel und in den Bronchulen des Kaninchens beträgt der Index sogar 90-120, und die Kerne haben kugliche Gestalt. Solche Kerne enthaltende Epithelien sind im allgemeinen dünner.

\section{9. Über die im Epithel basal liegenden Kerne.}

Die Länge und Breite der Kerne sind bei beiden Tieren $4-6 \mu$. Ihr Längen-Breitenindex beträgt meist 90-110. An der Nasenscheidewand des Kaninchens sind aber die Kerne ausnahmsweise queroval.

\section{Zusammenfassung.}

1. Die Epitheldicke nimmt von dem Vorderteil der Nasenhöhle bis zur Choana und umgekehrt von den Bronchulen bis zur Kehlkopfhöhle immer zu. Das Epithel ist an den Orten, in welchen die Luftströmung nur gering ist, wie in der Oberkieferhöhle und an der konkaven Fläche der Nasenmuschel, ziemlich dünn. Das Epithel ist in der Regel bei der Katze dicker als beim Kaninchen, ein Unterschied, der im unteren Luftwege bedeutender ist als im oberen.

2. Es besteht keine regelmäßige Beziehung zwischen der Höhe der Cilien und der Epitheldicke. Zwischen den Höhen der Cilien der beiden Tierarten gibt es auch keinen regelmäßigen Unterschied.

3. Der Variationskoeffizient der Breite der Flimmerzellen ist bei der Katze meist größer als beim Kaninchen. Der Unterschied ist besonders groß in den meisten Teilen des unteren Luftweges und an anderen einigen Stellen. Dies beruht hauptsächlich auf dem Gemenge von zahlreichen Übergangsformen zu verdickten Becherzellen.

4. Der Längen-Breitenindex der Flimmerzellen ist im allgemeinen bei der Katze kleiner als beim Kaninchen. Im unteren Luftwege der Katze ist der Index, mit Ausnahme der Bronchulen, unter 15.

5. Die Flimmerzellen in dem mehrreihigen Epithel verjüngen sich in der Höhe des unteren Endes des Kernes nach unten. Was oben bezüglich der Dicke des Epithels erwähnt ist, gilt auch von dem Hauptabschnitt der Flimmerzellen ohne den verjüngten Anteil.

6. Die im Epithel oben gereihten Kerne sind meist längsoval. Ihr Längen-Breitenindex ist gewöhnlich beim Kaninchen größer. In den dünnen Epithelien erscheinen sie aber kuglig. Die im Epithel am tiefsten liegenden Kerne sind kuglig. In dünnen zweireihigen Epithelien können sie sogar queroval sein. 


\section{内 容 自 抄。}

猫と家鬼の気道の上皮を測定して次の結果を得た。上皮は後鼻孔と喉頭 腔飞最も厚く，そこから前方と後方へ遠ざかるに従って薄い．上顎洞と鼻 介山面では上皮は特に薄い。上皮の厚さ，従って繊毛細胞の主部の長さは 主にそこの気流の機械的作用の強さに関係するらしい，上皮の上列にある 核は多くは長卵形であるが，薄い上皮のものは球形である，下列の核は殆 んどみな球形で，薄い 2 列上皮のものでは横卵形のこともある.

両動物を比較すると，上皮の厚さと繟毛細胞の幅の変異係数は猫に大で, 繊毛細胞の長幅示数は家鬼に大である，両動物間のこれ等の差も，杯細胞 と腺の量の差も，上気道よりも下気道に概して著しい.

\section{Literatur.}

Kusuhara, Y.: Die Histometrie des Epithels der Trachea und der Luftwege in der Lunge der Embryonen von Mensch, Kaninchen, Meerschweinchen und Ratte. Arch. hist. jap. 3 (1952). - Lonigoff, W. J.: Zur Morphologie der Flimmerzellen des Tracheaepithels einiger Haussäugetiere. Anat. Anz. 38 (1911). - Naganuma, K. : Über die Dicke des Epithels und der Basalmembran aus den verschiedenen Teilen der Nasenschleimhaut des Menschen. (Jap.) Kaibo. Z. 23 (1948). - Nakamura, F.: Air current in the nasal cavity and nasal function. (Jap.) J. of oto-rhino-laryngol. Soc. Jap. 54 (1951). - Oppikofer, E. : Beiträge zur normalen und pathologischen Anatomie der Nase und ihrer Nebenhöhlen. Arch. Laryngol. u. Rhinol. 19 (1906). - Rohrer, F. : Strömungswiederstand in den menschlichen Atemwegen. Pflügers Arch. 162 (1915).

Schumacher, S. : Histologie der Luftwege und der Mundhöhle. In Denkers und Kahlers Handbuch der Hals-Nasen-Ohrenheilkunde. Bd. 1, Tl. 1. Berlin. u. München 1925. 